\title{
Nutrient Recovery from Biodigestion Waste (Water) Streams and Reuse as Renewable Fertilizers: A Two-Year Field Experiment
}

Céline Vaneeckhaute ${ }^{1,2}$,

Greet Ghekiere $^{3}$, Evi Michels ${ }^{1}$, Peter A. Vanrolleghem ${ }^{2}$,

Erik Meers ${ }^{1}$, Filip M.G. Tack ${ }^{1}$

${ }^{1}$ Ghent University, Lab for Analytical and Applied Ecochemistry, Coupure Links 653, 9000 Ghent, Belgium

${ }^{2}$ Université Laval, modelEAU, Département de génie civil et de génie des eaux, Pavillon Adrien-Pouliot, 1065, avenue de la Médecine, Québec G1V 0A6, QC, Canada

${ }^{3}$ Inagro, Provincial Research and Advice Center for Agriculture and Horticulture, Ieperseweg 87, B-8800 Beitem, Belgium

\section{ABSTRACT}

The aim of this study was to evaluate the impact of using bio-digestion waste derivatives as substitute for synthetic fertilizers and/or as P-poor equivalent for animal manure on soil and crop production. In a field trial, nutrient balances were assessed and the physicochemical soil fertility and quality were evaluated. The biogas yield of the harvested energy crops was also determined. An economical and ecological evaluation was conducted. The highest biomass yields were obtained when the liquid fraction of digestate was used as P-poor fertilizer in addition to animal manure. Furthermore, the complete substitution of synthetic fertilizer $\mathrm{N}$ by air scrubber waste water resulted in the highest $\mathrm{N}$ and $\mathrm{P}$ use efficiencies. Finally, for all reuse scenarios the calculated economical and ecological benefits were significantly higher as compared to the common practice using animal manure and synthetic fertilizers.

\section{KEYWORDS}

Anaerobic digestion, digestate processing, cradle-to-cradle nutrient recycling, bio-based fertilizers, sustainable agriculture, environmental management.

\section{INTRODUCTION}

In the discussion concerning the rapid depletion of non-renewable fossil resources, one often only connotes to oil or natural gasses. However, several minerals such as $\mathrm{P}$ and $\mathrm{K}$ that are nowadays being extracted through mining, are also becoming scarce at a rapid pace. It is expected that the direct available resources of $\mathrm{P}$ will be completely depleted by the end of this century (Neset \& Cordell, 2012). Meanwhile, the demand for nutrients is still increasing. This imbalance between availability and demand will consequently raise the prices for nutrient resources considerably in the near future. At the same time a large proportion of minerals are again released in the environment in different waste streams, however often in hard-extractable form such as sewage sludge, industrial sludge, animal manure, domestic waste, incinerator ashes, etc. On their turn these waste streams can have detrimental ecological effects. In the transition from a fossil reserve-based to a bio-based economy, it is therefore an important challenge to maximally close the nutrient cycles and move to a more sustainable resource management, both from an economical and an ecological perspective.

Worldwide, an important nutrient source exists in digestates, which are produced as a waste stream during anaerobic digestion of animal manure, organic biological waste and/or energy maize. Although anaerobic digestion has been evaluated as one of the most energy-efficient and environmentally beneficial technologies for bio-energy production, the continued development of this technique is currently hindered in some regions, because the resulting digestates can often not or only sparingly be returned to agricultural land in their crude unprocessed form. This is especially the case in regions with high nutrient excesses, because 
of the stringent fertilization limitations within the scope of environmental legislation in these areas. Nevertheless, it has been shown that application of digestates could be beneficial due to their higher $\mathrm{C} / \mathrm{N}$-ratio and $\mathrm{N}$ uptake efficiency, as well as their lower $\mathrm{P} / \mathrm{N}$-ratio as compared to animal manure. Moreover, the consequent processing of digestates requires a variety of technologies, again resulting in different products with variable macro- and micronutrient composition, which could potentially be reused as green renewable fertilizers in agriculture. In this way sustainable substitutes for synthetic fertilizers based on fossil resources could be provided, while valuable nutrients are being recovered and recycled.

\section{DIGESTATE PROCESSING}

In general digestate processing starts with a mechanical separation into a liquid and solid fraction. Most of the $\mathrm{N}$ and $\mathrm{K}$ ends up in the liquid fraction (LF), while most of the organic matter, $\mathrm{P}, \mathrm{Ca}$ and $\mathrm{Mg}$ ends up in the solid fraction. In light of P-levels for soil application that become more and more strict in environmental legislation, reuse of this P-poor LF might be of particular interest in the near future. Furthermore, waste water resulting from $\mathrm{NH}_{3}$-removal by an acidic air scrubber could potentially be reused as formulated N-S-fertilizer, whereas concentrates resulting from membrane filtration of LF-digestate could potentially be reused as N-K-fertilizer. However, until now this has been difficult to realise due to obstacles in (national) legislative systems and lack of insights in the composition and properties of these products, as well as in their impact on crop yield and soil quality. Also policies regarding the use, transport, reuse, recycling and disposal of nutrients are currently often not harmonized between regions, and thus conflicts may easily arise.

\section{FIELD EXPERIMENT}

The aim of this study was to demonstrate the fertilizer potential of digestates and its derivatives by means of a two-year field trial in which eight different cultivation scenarios were compared in four replicate subplots $(n=4)$ (Table 1). In these scenarios LF-digestate from mechanical separation, waste water from an acidic air scrubber for $\mathrm{NH}_{3}$-removal, and a mixture of raw digestate and LF-digestate were applied to soil, either as substitute for synthetic fertilizers and/or animal manure for the cultivation of energy maize. The test site was located in Wingene, Belgium and concerns a 0.8 ha large sandy-loam field.

Table 1 Eight different fertilization scenarios (Sc) expressed as workable nitrogen $\left(\mathrm{kg} \mathrm{ha}^{-1}\right)$; Additional application of synthetic $\mathrm{K}_{2} \mathrm{O}\left(\mathrm{kg} \mathrm{K}_{2} \mathrm{O}\right.$ ha $\left.^{-1}\right)$; Dosage of $\mathrm{P}_{2} \mathrm{O}_{5}\left(\mathrm{~kg} \mathrm{P}_{2} \mathrm{O}_{5} \mathrm{ha}^{-1}\right)$.

\begin{tabular}{|c|c|c|c|c|c|c|c|c|c|c|}
\hline Scenario & Group $^{a}$ & Year & $\begin{array}{l}\text { Synthetic } \\
\text { starter N }\end{array}$ & $\begin{array}{c}\text { Synthetic } \\
\text { N }\end{array}$ & $\begin{array}{c}\text { Air } \\
\text { scrubber } \mathbf{N}\end{array}$ & $\begin{array}{l}\text { Animal } \\
\text { manure }\end{array}$ & $\begin{array}{l}\text { Digestate } \\
\text { mixture }\end{array}$ & $\begin{array}{l}\text { Liquid fraction } \\
\text { digestate }\end{array}$ & $\begin{array}{c}\text { Synthetic } \\
\mathrm{K}_{2} \mathrm{O}\end{array}$ & $\mathrm{P}_{2} \mathrm{O}_{5}{ }^{\mathrm{b}}$ \\
\hline \multirow[t]{2}{*}{1} & 0 & 2011 & 25 & 29 & & 96 & & & 78 & 80 \\
\hline & 0 & 2012 & 30 & 30 & & 75 & & & 213 & 80 \\
\hline \multirow[t]{2}{*}{2} & 1 & 2011 & 25 & & 29 & 96 & & & 78 & 80 \\
\hline & $T$ & 2012 & 30 & & 30 & 75 & & & 213 & 80 \\
\hline \multirow[t]{2}{*}{3} & $T$ & 2011 & & & 54 & 96 & & & 78 & 80 \\
\hline & $T$ & 2012 & & & 60 & 75 & & & 213 & 80 \\
\hline \multirow[t]{2}{*}{4} & II & 2011 & 25 & 18 & & & 107 & & 29 & 80 \\
\hline & II & 2012 & & & & & 134 & & 0 & 80 \\
\hline \multirow[t]{2}{*}{5} & II & 2011 & 25 & & 18 & & 107 & & 29 & 80 \\
\hline & II & 2012 & 33 & & & & 102 & & 46 & 61 \\
\hline \multirow[t]{2}{*}{6} & II & 2011 & & & 43 & & 107 & & 29 & 80 \\
\hline & II & 2012 & & & 33 & & 102 & & 46 & 61 \\
\hline \multirow[t]{2}{*}{7} & III & 2011 & 25 & & & 84 & & 35 & 33 & 77 \\
\hline & III & 2012 & 33 & & & 67 & & 35 & 121 & 76 \\
\hline \multirow[t]{2}{*}{8} & III & 2011 & & & & 78 & & 59 & 0 & 76 \\
\hline & III & 2012 & & & 33 & 67 & & 35 & 121 & 76 \\
\hline
\end{tabular}

${ }^{\text {a }}$ Group: 0 = Reference: conventional fertilization, I = Substitution of synthetic fertilizer N by air scrubber water, II = Anaerobic digestion of animal manure and field application of digestate with or without substitution of synthetic fertilizer $\mathrm{N}$ by air scrubber water, III = Use of LF digestate as P-poor fertilizer in addition to animal manure with or without the substitution of synthetic fertilizer $\mathrm{N}$ by air scrubber water. ${ }^{\mathrm{b}} \mathrm{No}$ synthetic $\mathrm{P}_{2} \mathrm{O}_{5}$ was added. 
Based on the soil characteristics, the fertilization advice was formulated at $150 \mathrm{~kg}$ effective $\mathrm{N}$ $\mathrm{ha}^{-1}, 180 \mathrm{~kg} \mathrm{~K}_{2} \mathrm{O} \mathrm{ha}{ }^{-1}$ and $30 \mathrm{~kg} \mathrm{MgO} \mathrm{ha}^{-1}$ in 2011, and 135, 250 and $60 \mathrm{~kg} \mathrm{ha}^{-1}$ in 2012. For $\mathrm{P}_{2} \mathrm{O}_{5}$, the maximum allowable dosage of $80 \mathrm{~kg} \mathrm{ha}^{-1}$ for the cultivation of maize was respected as described in the Flemish manure regulation. In order to evaluate the potential environmental impact using these bio-based products in agriculture, nutrient balances were assessed and the physico-chemical soil quality, including the nitrate residue, leaching, electrical conductivity (EC), $\mathrm{pH}$, organic carbon content, sodium adsorption ratio (SAR), as well as $\mathrm{P}$ and heavy metal accumulation were evaluated. The biogas yield of the harvested energy crops was determined in 2011 by means of an anaerobic digestion batch test. As such, the nutrients coming from the digestate are again recycled to the anaerobic digestion plant and nutrient cycles are maximally closed. Finally, an economical and ecological evaluation was conducted for use of these products as compared to the conventional scenario using animal manure additionally supplied with synthetic fertilizers (Vaneeckhaute et al., 2013).

\section{FERTILIZER IMPACT ON CROP PRODUCTION AND BIOGAS POTENTIAL}

Over the whole experimental period, the average biomass yields were the highest when LFdigestate was used as P-poor fertilizer in addition to animal manure (Sc 7-8). This effect was significant at the harvest in 2012, when Sc 4 showed a significantly lower dry weight (DW) and fresh weight (FW) yield than Sc 1, 7 and 8, and Sc 5 showed significantly lower yields than Sc 8 at the $5 \%$ significance level. In 2011, the FW-yield was also significantly higher for Sc 7 and 5 as compared to Sc 2 . The average DW-content at the harvest was $28 \pm 1 \%$ in 2011 and $29 \pm 0 \%$ in 2012. Hence, the energy maize was suitable for biogas production (desired 28$36 \%$ ). Biogas batch tests in 2011 showed little effect of the fertilizers applied on the biogas potential of the harvested crops $\left(307 \pm 13 \mathrm{~m}^{3} \mathrm{t}^{-1} \mathrm{DW}\right.$ in average). However, the energetic potential per hectare was higher for Sc 4-7 compared to Sc 1-3 due to the higher average FW biomass yield in these scenarios.

\section{FERTILIZER IMPACT ON SOIL FERTILITY AND SOIL QUALITY}

No significant differences in $\mathrm{NO}_{3}-\mathrm{N}$ residue in the soil were observed between the different fertilizations, except in November 2011, when Sc 5 showed significantly higher residues than Sc 2, 4, 6 and 8. It should, however, be remarked that at this time all scenarios exceeded the Flemish environmental standard of $90 \mathrm{~kg} \mathrm{NO}_{3}-\mathrm{N} \mathrm{ha}^{-1}$ due to exceptional weather conditions (dry spring, wet summer and hot autumn). In November 2012, all scenarios showed a nitrate residue below the limit of $90 \mathrm{~kg} \mathrm{ha}^{-1}$ and no significant differences between the fertilizations were observed. Nevertheless, there was a strong significant effect of the fertilizers applied on the $\mathrm{N}$ use efficiency (NUE $=\mathrm{N}$-uptake/application by fertilization) and the plant $\mathrm{N}$-uptake (kg $\mathrm{ha}^{-1}$ ) in 2012. The scenarios in which synthetic fertilizer $\mathrm{N}$ was completely replaced by air scrubber water (Sc 3 and especially Sc 8) showed the highest NUE and plant N-uptake. Also a strong significant correlation was found between the NUE and the DW biomass yield $(\mathrm{r}=$ 0.801). Finally, model simulations of $\mathrm{N}$ dynamics in agriculture indicated that the amount of $\mathrm{N}$-leaching to ground and surface waters decreased significantly as more synthetic $\mathrm{N}$ was replaced by air scrubber water, while the amount of $\mathrm{N}$-volatilization only slightly increased.

At each sampling time the $\mathrm{P}$ use efficiency ( $\mathrm{PUE}=\mathrm{P}_{2} \mathrm{O}_{5}$-uptake/application by fertilization) was significantly different for the various scenarios. In 2011, the application of digestate with or without the substitution of synthetic fertilizer $\mathrm{N}$ by air scrubber water (Group II) resulted in significantly higher PUE's, while the P-dosage was the lowest. However, in 2012, the PUE's were the lowest for this group, while the P-dosage was the highest. The plant P-uptake over 
time was thus clearly not correlated $(\mathrm{r}=0.091)$ to the P-dosage to the field. Therefore, regarding the imminent depletion of P-reserves, the use of products with low P-content should be preferred. In 2012, the plant P-uptake was significantly higher for the scenarios in which synthetic fertilizers were completely substituted by air scrubber waste water (Sc 3, 6 and 8) as compared to the reference. The higher P-uptake in these scenarios may be attributed to the higher dosage of $\mathrm{NH}_{4}-\mathrm{N}$ by the air scrubber water. Indeed, the uptake of $\mathrm{NH}_{4}{ }^{+}$by the roots, as well as the nitrification of $\mathrm{NH}_{4}{ }^{+}$into $\mathrm{NO}_{3}{ }^{-}$are acidifying processes, which can increase soil $\mathrm{P}$ mobilization and uptake in the rhizosphere. Hence, the P-uptake was also highly correlated to the NUE $(r=0.932)$ and the plant $N$-uptake $(r=0.844)$.

In the long term (2 years) no significant effect of the fertilizer applied on the soil EC, the pH$\mathrm{H}_{2} \mathrm{O}, \mathrm{pH}-\mathrm{KCl}$, the SAR and the soil sulphur content was observed. Nevertheless, in all scenarios the Flemish environmental soil standard for $\mathrm{Cu}$-accumulation was exceeded, but this is likely the legacy of historical overfertilization. No other heavy metal accumulation has been observed thus far. A final interesting point is that significantly more organic carbon was applied to the field in the scenarios in which digestate derivatives were used (Sc 4-8). Recycling of these products could therefore also contribute to the struggle against organic carbon depletion in many soils world-wide.

\section{TECHNICAL AND LEGISLATIVE IMPLICATIONS}

It is clear that waste water from an acidic air scrubber for ammonia removal can be used as a valuable N-S-rich mineral fertilizer. However, it is not often applied up to now due to legislative constraints and farmers' distrust. Therefore it is highly important that the results obtained in this study are widely spread and that the use of this product is stimulated in European legislation. Environmental technical solutions are required to neutralize the $\mathrm{pH}$ of this waste stream in a practical, economical and ecological way. Also modified or new application techniques should be investigated for this new type of fertilizer and/or methods to concentrate the $\mathrm{N}$-content in an economical and ecological way should be developed.

\section{ECONOMICAL AND ECOLOGICAL EVALUATION}

The application of bio-based fertilizers in agriculture can result in significant economical benefits for the farmer, as well as ecological benefits through the reduction of energy use and green house gas (GHG) emissions. The economical and ecological benefits were the highest for Sc 8, respectively 3.5 and 4.4 times higher than the reference, as both chemical $\mathrm{N}_{\text {and }} \mathrm{K}_{2} \mathrm{O}$ were completely eliminated in this scenario. Reuse of biodigestion waste (water) streams can thus improve the economic viability of anaerobic digestion plants, especially in high-nutrient regions. This in turn can serve as a catalyst to meet the 2020 EU directives aiming at a $20 \%$ reduction in GHG emissions, a $20 \%$ cut in energy consumption through improved energy efficiency and a $20 \%$ increase in the use of renewable energy by 2020 compared to 1990 .

\section{REFERENCES}

Neset, T.S, Cordell, D (2012) Global phosphorus scarcity: identifying synergies for a sustainable future; J Sci Food Agric 92: 2-6

Vaneeckhaute, C, Meers, E, Michels, E, Buysse, J, Tack, F.M.G (2013) Ecological and economic benefits of the application of bio-based mineral fertilizers in modern agriculture; Biomass Bioenerg 49: 239-248 